\title{
A "integração" dos imigrantes brasileiros na França
}

\author{
Gisele Maria Ribeiro de Almeida *
}

Existe uma expressão polêmica bastante utilizada na França que é o "français de souche" - cuja tradução literal seria "francês de estirpe". Utilizada no contexto da presença de estrangeiros e de imigrantes no país, a expressão geralmente evoca uma marcação distintiva, por referir-se aos franceses que possuem ascendência majoritariamente ou totalmente francesa tendo em vista os franceses naturalizados e aqueles cujas famílias são de origem estrangeira. Segundo estimativas da demógrafa francesa Michèle Tribalat, em 1999 havia 14 milhões de franceses imigrantes ou que tinham pais ou avós de origem estrangeira, número que representa um quarto da população francesa (TRIBALAT, 2004). Isso porque a França apresentou historicamente baixas taxas de natalidade, um crescimento populacional modesto que repercutiu em escassez de trabalhadores. Neste contexto, ao longo do século XX foram executadas políticas de atração de trabalhadores estrangeiros. Após a 2a Guerra Mundial, o recrutamento foi institucionalizado com a criação do "Office National d'Immigration", órgão estatal concebido para gerenciar a vinda de trabalhadores estrangeiros e administrar os processos de assimilação e de repatriamento relacionados, perdurando até 1974, quando foi anunciada a suspensão oficial da imigração, com exceção do direito de asilo e da reunificação familiar (WEIL, 2004).

Quando se discute politicamente a imigração na França, o uso do termo "integração" aparece frequentemente associado. Um Ministério Francês criado em 2007, pelo então presidente Nicolas Sarkozy, foi intitulado como "Ministério

*Doutoranda em Sociologia no IFCH/UNICAMP e bolsista da FAPESP. 
da Imigração, da Integração, da Identidade Nacional e do Codesenvolvimento". Segundo Stoicea-Deram (2009), a criação do Ministério e a reunião dos termos mencionados gerou diversas reações, pois no "espírito" em que foi concebido era como dizer: "a imigração traz problemas à integração, ameaça à identidade nacional, para limitá-la é necessário investir em codesenvolvimento" (p. 31) ${ }^{1}$.

Em 2009, o tal Ministério foi suprimido e a gestão da imigração ficou a cargo do Ministério do Interior. Com a vitória de François Hollande do Partido Socialista, em 2012, houve uma expectativa de reforma do Ministério, tendo em vista as críticas de que sob a alçada do Ministério do Interior impera a visão policialesca sobre a imigração. No entanto, o governo de Hollande manteve tal disposição e atualmente a "Secretaria Geral de Imigração e Integração" funciona no âmbito do Ministério do Interior. E mais uma vez, "imigração" e "integração" aparecem reunidas.

Ainda que esta análise não se faça pela perspectiva da linguística, a junção de tais expressões na composição dos órgãos públicos responsáveis pela gestão da política migratória foi tomada como um ponto de partida para refletirmos sobre a condição do "estrangeiro" na sociedade francesa contemporânea ${ }^{2}$. Considero relevante apontar, no entanto, que tratarei aqui de um processo social, e este não se realiza sem divergência ou conflitos, e neste sentido reconheço que não há uma uniformidade ideológica entre todos os cidadãos franceses.

\section{A nação e o estrangeiro}

Hobsbawm (2005) afirma que a nação é um artefato, sua gênese não foi espontânea, sendo, ao contrário, meticulosamente construída pela capacidade que algumas instituições tiveram em construir a uniformidade nacional. Esse processo envolve desafios objetivos (como fazer com que todos falem a mesma língua) e subjetivos, porque depende da construção dos elos simbólicos e ideológicos que ligam os indivíduos à nação. A nação para existir precisa ancorar-se em sentimentos nacionalistas, e estes se instituem no âmbito das representações sociais.

São os elementos compartilhados que compõem, ao nível das representações, a identidade da nação. Aqueles que compartilham tais representações e ao mesmo tempo são por elas reconhecidos serão incluídos na nação e terão o status de cidadão nacional. Entretanto, esse processo é automática e simultaneamente um processo de exclusão. Esta exclusão se dá tanto em relação ao "estrangeiro", cuja origem é externa às fronteiras nacionais, bem como ao "estrangeiro" no interior da nação, em função de especificidades identitárias que não são incorporadas no universal que se amalgama na identidade nacional. Como espero argumentar, tal estratificação engendra condições favoráveis para processos de estigmatização.

Elias e Scotson (2000) argumentam que a sociodinâmica da estigmatização é um processo que nasce das relações sociais estabelecidas entre grupos com poder diferenciado. Nestes casos, os grupos mais poderosos tendem a construir 
uma autoimagem de superioridade frente aos outros e a engendrar estigmas sobre eles. Quando se pensa a identidade cultural e o sentimento nacionalista, tem-se um caminho que define o pertencimento a um determinado grupo (os compatriotas) a partir de fronteiras bem desenhadas, e que estabelecem como contrapartida as marcas dos outsiders. Conterrâneos da nação e "estrangeiros" constituem grupos sociais distintos, cujas relações estão permeadas por relações desiguais de poder. Aspecto que é necessário, de acordo com Elias e Scotson, para engendrar as condições que viabilizam a instituição de processos sociais de estigmatização. Se no estudo de caso de Elias e Scotson os grupos diferenciavamse pelo tempo de residência num determinado local - os mais antigos e os "novos" moradores -, a Nação e o sentimento nacionalista, por sua vez, criam as diferenças entre os cidadãos nacionais e os "estrangeiros".

\section{"Integração" à francesa}

O estudo sobre a adaptação dos imigrantes nas sociedades de acolhimento começou muito mais tarde na França, em comparação aos Estados Unidos, com as contribuições da chamada Escola de Chicago. Segundo Schnapper (2007), isso se deve ao fato do "projeto de integração republicana" criar a "fiç̧ão da igualdade entre os cidadãos", o que tornava ilegítimo o tema da integração do imigrante na França. Neste sentido, revela-se a tradição "assimilacionista" do modelo francês, que foi colocado em cheque principalmente no último quartel do século XX. Quando se deu a suspensão oficial da política de imigração e a consequente alteração na composição do fluxo, com aumento expressivo da modalidade de reagrupamento familiar, foi evidenciado que os "imigrantes" iriam ficar definitivamente. Aí, sim, o tema da integração começou a despertar interesse.

Concebida politicamente, fundada pelo contrato social, a cidadania francesa não depende da origem étnica e, como uma sociedade de imigração, a França precisa forjar a unidade política nacional tendo em vista a diversidade de origem dos seus cidadãos. Neste sentido, para "incorporar" a população estrangeira junto à sociedade francesa, foram adotadas políticas de integração nas últimas décadas. Uma prova deste esforço está na instituição do "Alto Conselho para a Integração" - originalmente Haut Conseil à l'integration. O referido Conselho foi criado por decreto em 1989 e tem por objetivo elaborar análises e sugerir encaminhamentos políticos no que se refere ao conjunto das questões relativas à integração dos residentes estrangeiros ou de origem estrangeira. O Conselho é composto por cerca de vinte membros, que exercem funções variadas (políticos, jornalistas, cientistas, entre outros) e que elaboram relatórios anuais. O primeiro relatório, lançado em 1991, foi intitulado "Por um modelo francês de integração" ${ }^{3}$ e apresenta o quadro referencial que, segundo o Conselho, deve orientar os gestores públicos na definição de políticas voltadas à integração. Um aspecto interessante deste relatório é a explicitação de uma definição de integração. De 
acordo com o texto, a assimilação enfatiza a unidade da comunidade nacional, enquanto a inserção refere-se às condições de acolhimento dos estrangeiros, mas com a manutenção dos laços com a origem. Neste sentido, o relatório explicita que integrar não significa assimilar, nem inserir. A integração é um processo que garante a escolha e a participação dos novos membros na comunidade nacional (HAUT CONSEIL À L'INTEGRATION, 1991).

Tendo em vista esta concepção de integração, a política voltada para tal fim implica na possibilidade de adesão de todos a um mínimo de valores comuns, a aceitação de um quadro de referência compartilhado a despeito das diferenças que possam existir.

\section{A imigração brasileira na França pós-1980}

Historicamente, o Brasil foi um país de imigração, mas desde 1980 iniciou-se um processo de emigração. Em grande medida, tal fato pode ser explicado pela grave crise econômica vivenciada pelo país naquele contexto, com impactos para o mercado de trabalho, particularmente sobre as classes médias (SALES, 1995). Em um primeiro momento, os principais destinos foram Estados Unidos, Japão e Portugal. Mais recentemente, o número de brasileiros tem crescido em outros países como Alemanha, Bélgica e França, muito provavelmente em função do espaço de livre circulação europeu e das oportunidades para os imigrantes brasileiros naquele continente (ROSENFELD et al, 2009).

O espaço de livre circulação europeu é particularmente importante no fluxo pesquisado dada a não exigência de visto para deslocamentos de curta duração (estada inferior a 90 dias), em função de um acordo assinado entre o Brasil e a França, e que vigora desde 1996. Assim, desde então, este país europeu tornou-se, ao menos de forma potencial, uma porta de entrada para o brasileiro naquele continente. Aspecto que ganha ainda mais relevância se considerarmos a presença expressiva de brasileiros na Inglaterra e das maiores restrições que a política inglesa vem impondo para a entrada e a permanência de estrangeiros.

Os dados do Instituto Nacional de Estatística e de Estudos Econômicos (INSEE) de 2008 apontam que os brasileiros representavam um quinto da população latino-americana na condição de estrangeiros e imigrantes na França. Os imigrantes, conforme a definição do INSEE, são os brasileiros que vivem na França e nasceram no Brasil, e que obtiveram a nacionalidade francesa. Os estrangeiros são os brasileiros que moram na França (e que não foram naturalizados franceses). Os imigrantes brasileiros eram 5.300 em 1982 e 25.000 em 2008. Os estrangeiros também apresentaram crescimento: 3.800 em 1982 e 14.000 em 2008. Obviamente, estes números são oficiais e tendem a revelar apenas a presença brasileira em situação migratória regular no país. De acordo com as estimativas do Ministério das Relações Exteriores do Brasil ${ }^{4}$, os brasileiros na França foram estimados em 80 mil (dados que apontam para o crescimento deste grupo nos últimos anos). 
Do ponto de vista da sociedade de acolhimento, a participação dos brasileiros no que se refere ao total de estrangeiros e imigrantes na França é irrisória: menos de $1 \%$. No entanto, as representações do Brasil e dos brasileiros na França que vieram à tona nas entrevistas realizadas dão indícios de que há estereótipos bem consolidados, que são tomados aqui como elementos para refletirmos sobre os processos de "integração" dos imigrantes brasileiros na França.

\section{Formas e processos de integração dos brasileiros na França}

Existem relações históricas e específicas entre o Brasil e a França que parecem ter servido para alimentar representações dos brasileiros sobre a França e de franceses sobre o Brasil. Estas podem ser classificadas de amistosas e neste sentido, configuram a princípio um encontro harmonioso entre franceses e brasileiros. No entanto, numa análise mais atenta é possível encontrar evidências de que os percursos de integração dos imigrantes brasileiros à sociedade francesa estão permeados por obstáculos, que evidentemente não são os mesmos para todos os tipos de imigrantes. A discussão será feita aqui tendo como base uma pesquisa de campo empreendida no âmbito do meu doutoramento e que permitiu a realização de entrevistas semiestruturadas com imigrantes e eximigrantes brasileiros na França ${ }^{5}$.

Ainda que muitos franceses desconheçam a realidade do Brasil, há também uma imagem do país e dos brasileiros bastante difundida pela mídia francesa. Imagem que se foi restrita aos estereótipos dos trópicos (praia, caipirinha, samba e futebol), nos últimos anos vem sendo também associada à política e à economia do país. Como exemplo, em 2010, uma revista de economia francesa chamada L'Expansion dedicou um número especial ao Brasil, intitulado "Brasil, o novo eldorado francês", cuja foto de capa era a estátua do Cristo Redentor na cidade do Rio de Janeiro segurando uma bandeira da França, onde se via logotipos de empresas francesas. Ainda que muitos entrevistados tenham mencionado esta mudança no olhar da França sobre o Brasil, consolidados estigmas sobre o Brasil e o brasileiro e a brasileira continuam a se manifestar e em alguns casos, gerando nos brasileiros entrevistados sentimentos de discriminação e apontando limites para a "integração" destes imigrantes.

Abud (2010) analisou representações sobre a identidade nacional brasileira tendo em vista os imigrantes e as associações brasileiras na cidade de Lyon e segundo apontou, estas "marcas identitárias" podem funcionar para a inclusão ou para a exclusão; a autora argumentou como a imagem de "povo alegre" pode ser um facilitador para a aceitação destes "estrangeiros" pelos autóctones franceses, e como a imagem sexualizada da mulher brasileira pode ser um obstáculo para sua inserção na sociedade francesa.

Por outro lado, Amorim (2009) mostrou que o imaginário dos franceses sobre o Brasil é repleto de ideias de cunho afetivo, que reverberam em relações de amor, com o país e com suas mulheres, estimulando a imigração de franceses 
para o Brasil e promovendo casamentos com as brasileiras ${ }^{6}$. Este aspecto da representação da mulher brasileira pelo francês merece destaque, por ser o fator de discriminação que apareceu com mais frequência nas entrevistas realizadas. A seguir, reproduzimos dois trechos de entrevistas sobre essa questão:

A mulher brasileira, ela tem mito, que cria medo, (...) é o mito do sexo fácil (...) e solteira ou casada, a única particularidade que eu vi, sendo um ponto em comum na Europa é o seguinte: quando [uma pessoa] está falando comigo, sendo grata, está tudo bem (...) dali um pouco: 'da onde é que tu vens?'. 'Eu sou brasileira!'. De repente você olha, se é um homem, o olho parece assim que salta da órbita e fica te imaginando como se você tivesse 'trepando' agarrada no lustre. (...) O olhar modifica completamente ${ }^{7}$. [Silvana, 44 anos, casada com francês, vive na França desde 1993].

Eu acho que mulher brasileira é bem discriminada (...) é aquela questão sexual. Sempre! Numa festa quando tu conversas com um francês ou qualquer europeu, estrangeiro: 'tu és brasileira! Hummm!'. Já tem um "hummm', sabe, na conversa, então, eu não costumo falar que eu sou brasileira (...) eu não falo porque eles têm uma malícia com as brasileiras, é uma discriminação bem forte ${ }^{8}$. [Bianca, 26 anos, vive na França desde 2011].

Silvana e Bianca são ambas do sul do Brasil e foram para a França com a mesma motivação inicial: estudar. Mas ao mesmo tempo são situações bem diferentes, pois Silvana têm 44 anos e vive lá há 20 anos, enquanto Bianca tem 26 anos e é recém-chegada no país. Estas duas mulheres, que estão em etapas diferentes da sua "carreira migratória", compartilharam o mesmo incômodo e mal-estar diante do estereótipo da brasileira. Outras entrevistas mencionaram a questão da imagem sexualizada da brasileira, mas mostraram-se menos afetadas. Valentina, 35 anos, está fazendo seu doutorado numa Universidade no sul da França desde 2012 e contou-me que não viveu "nenhuma situação desagradável" porque sabe "manter a distância", mas disse que acha que "mulheres mais tranquilas, devem ter problemas" doutoramento na região parisiense, atuando numa área que tem mais homens que mulheres, disse que mesmo assim nunca se sentiu pessoalmente vítima deste tipo de preconceito, mas admitiu que "a gente ouve muita coisa, muita piada em torno da brasileira"10.

De acordo com Almeida Rego e Christiano (2012), o estrangeiro é um tema recorrente de piadas e gozações porque é uma figura vista como extravagante. Ele é o "desviante" e "excêntrico" que tende a se constituir em objeto de riso por ser visto como "exótico" culturalmente e também por aspectos relacionados ao idioma (falta de habilidade que o leva a cometer erros, presença de sotaque, 
etc.). Por outro lado, os autores reconhecem que imagens estereotipadas de conotação sexual servem para alimentar os clichês que serão desenvolvidos pelo humor. O problema para a "integração" dos "estrangeiros" é que estes clichês acabam por fundamentar representações que podem servir à desqualificação do outro (país e cidadão) e estar na raiz da adoção de atitudes preconceituosas.

Este é o caso de uma fisioterapeuta brasileira, Daniela, 30 anos, que durante uma especialização na França precisou fazer estágio num hospital francês. Em entrevista, Daniela contou-me que a fisioterapeuta responsável lhe perguntou se no Brasil as fisioterapeutas "dançavam para os pacientes"11. Diante das dificuldades para se relacionar no ambiente de trabalho, Daniela acabou procurando outro hospital para continuar seu estágio.

Ainda que não tenha como objetivo fazer uma discussão sobre gênero, devo dizer que as mulheres entrevistadas se queixaram mais do que os homens entrevistados. Outro aspecto a destacar sobre estas diferenças em relação ao sexo, é que o "lugar" que a brasileira ocupa na sociedade francesa também é um elemento importante. Ser manicure ou atendente num café parece ser uma posição mais protegida do que ser uma profissional altamente qualificada. Quando o estrangeiro é "a brasileira", e esta se afasta demais do "lugar" que lhe cabe nos imaginários constituídos, parece que a tendência a ser discriminada pelos franceses aumenta. Digo isso porque profissionais qualificados de ambos os sexos narraram percepções bastante distintas: dois homens me disseram não sofrer preconceito por serem estrangeiros, em função de um reconhecimento técnico e profissional. Por sua vez, duas mulheres, também qualificadas e competentes para a função exercida, alegaram que foram confrontadas com práticas hostis no ambiente de trabalho e declararam-se vítimas frequentes de preconceito no campo profissional.

Em relação aos estereótipos, é preciso mencionar também o uso estratégico que os brasileiros e as brasileiras podem fazer acerca dos clichês estabelecidos. Esse tipo de discriminação de efeito "positivo" aplica-se claramente aos artistas brasileiros na França. Humberto, 44 anos, vive lá desde 2004, declarou que não se sente discriminado, mencionando o fato de ser "branquinho" e de ser "músico"12. Outro músico, César de 28 anos, é negro e também disse não sentir discriminação, mas reconhece que sendo músico, a "relação é diferente" ${ }^{13}$.

Desta forma, músicos e professores de capoeira podem se beneficiar dos estereótipos sobre o Brasil quando estão vivendo e trabalhando na França. Show de música brasileira, com músicos brasileiros e bailarinas brasileiras é um "produto" que "agrada" e é bastante vendido e consumido enquanto tal, principalmente no sul da França durante o verão. Assim como em noites de forró ou de rodas de samba em bares parisienses.

Por outro lado, existe também uma parcela de brasileiros na França que foram muito bem "integrados". Em linhas gerais isso significa, segundo os próprios depoimentos: ter fluência no idioma francês, trabalhar formalmente, ter uma situação jurídica estável (título de residente ou naturalização francesa). 
Um indicativo do nível de integração dos imigrantes, segundo a política de integração francesa, refere-se ao acesso à cidadania francesa. Como o número de casamentos franco-brasileiros é grande entre o universo de entrevistados, há dezenas de casos em que a união cumpriu papel fundamental na obtenção da cidadania. No entanto, há também ocorrências de brasileiros que se tornaram franceses em função do tempo de residência na França, entre outros aspectos que atendem aos requisitos legais para efetivar as naturalizações. A família de Margareth ${ }^{14}, 42$ anos, mudou-se para a França em 1999, quando o marido foi enviado através de um contrato de expatriação de uma empresa francesa no Brasil. O casal e os dois filhos viveram lá até 2009, quando voltaram ao Brasil, novamente em função do trabalho do marido. Durante a estada na França, eles obtiveram a nacionalidade francesa, no entanto, seu depoimento insistiu que o reconhecimento jurídico não se traduziu necessariamente em reconhecimento social e que o rótulo de "estrangeira" tende a permanecer.

Há brasileiros que vivem na França com visto de estudante, renovado anualmente, o que significa viver numa instabilidade. Nesses casos, muitos querem ficar na França, mas precisam garantir as condições para tanto. Desta forma, há experiências cuja palavra-chave é "insegurança", porque não sabem o que vai acontecer no futuro, na próxima data de renovação do visto.

Para aqueles que vivem irregularmente no país, a situação tende a ser ainda mais precária. No entanto, há os que dão um "jeitinho" e encontram alternativas e brechas no sistema social francês. Alguns brasileiros em situação irregular declararam ter acesso à assistência médica e outros benefícios sociais. Mas isso não significa que não exista brasileiros vivendo à margem do Estado e da sociedade francesa, sobrevivendo graças ao apoio de redes pessoais.

Outro fator a destacar é a recorrência com que ouvi dos entrevistados que os franceses gostam do Brasil e do brasileiro e que por isso, os brasileiros que lá vivem não encontram muitos problemas, ao contrário, são geralmente muito bem recebidos. Essa "invisibilidade" da discriminação pode ser uma faceta do que alguns autores têm discutido em termos de negação da existência de racismo (SIMAI e BAENINGER, 2012). Esta negação está ausente quando se trata dos "árabes", expressão utilizada pelos próprios entrevistados para se referir aos "estrangeiros" que constituem o alvo da xenofobia francesa. Diversos entrevistados declararam que os franceses não gostam dos "árabes" porque estes não aceitam viver como os franceses e insistiram que o brasileiro sabe respeitar a cultura francesa. Inclusive, alguns dos entrevistados disseram concordar que a imigração "árabe" é um problema para a França porque eles não se "integram".

\section{Considerações finais}

O uso político da crise da identidade nacional, associada à imigração, é um caminho perigoso, por enfatizar a delimitação das fronteiras que constituem o "nós" - integrantes da nação -, e os "outros" - estrangeiros. Levada ao extremo, 
essa construção nega o reconhecimento do outro e acaba por se traduzir em xenofobia.

A política migratória francesa tem, desde meados dos anos 1990, "fechado o cerco". Uma série de medidas foi instituída para aumentar as restrições relativas à entrada e à permanência de estrangeiros no país. No bojo desta dinâmica, a discussão sobre a identidade nacional aparece combinada ao perigo "estrangeiro". O debate sobre identidade nacional poderia ser frutífero ao estimular reflexões sobre a diversidade que a constitui, ao favorecer o "jogo de espelhos", através do qual aprendemos mais sobre "nós" e sobre os "outros" simultaneamente. Mas ao servir aos fins políticos, o tal debate parece favorecer mais a desintegração social do que a incorporação do imigrante na sociedade francesa. Diante da crise do Estado-Nação, do colapso do Estado Providência e da instabilidade econômica, encontrar nos "estrangeiros" as causas do problema, pode ser uma "solução" para a agenda política, mas não uma "solução" para a crise social.

É nesta França, e diga-se, nesta Europa, que os brasileiros em questão estão vivendo ou chegando. De acordo com as entrevistas realizadas, alguns brasileiros realmente encontram dificuldades para permanecerem legalmente no país, o que resulta em situações de irregularidade ou ainda de decisão de retorno ao Brasil. Importante dizer que o sentimento e a percepção de ser discriminado como "estrangeiro", mesmo quando se trata de imigrantes em situação regular, foi apontado como motivo importante para voltar. As palavras de Vânia sobre essa questão são contundentes:

Eu fiquei me olhando, eu falei assim, eu vou ter que passar o resto da minha vida justificando porque eu estou aqui - porque era isso que eu tinha que responder todo santo dia. Alguém sempre me cruzava e falava: "você tem um acento, você tem um sotaque, de onde você é? O que você está fazendo aqui?". "Mas o Brasil, o Brasil é um país lindo, o que você está fazendo aqui?". O "fazendo aqui" deles não era assim: "puxa, o que você está fazendo aqui!?" [tom de curiosidade]. Não era: "o que você está fazendo aqui, teu país é tão maravilhoso!" [tom de gentileza]. Na verdade, estava subentendido: "o que você está fazendo aqui, tirando um emprego nosso. O que você está fazendo aqui, estrangeiro!". Eu comecei a perceber que esse "o que você está fazendo aqui?", não era elogioso, era simplesmente, você está tomando o lugar de alguém que está lá fora ${ }^{15}$. [Vânia, 47 anos, separada, viveu na França dez anos].

Procurei reunir neste texto um pouco da diversidade das modalidades migratórias encontradas, bem como as diferentes percepções frente a experiência como estrangeiro; neste sentido, parece-me necessário insistir no caráter 
heterogêneo da "comunidade" brasileira na França e enfatizar a existência de distintas trajetórias que percorrem caminhos específicos rumo à inserção na sociedade de destino. $O$ que encontramos são processos de discriminação e integração multifacetados e às vezes paradoxais.

\section{Notas}

1 - Tradução livre do original em francês: "l'immigration pose de problèmes à l'intégration, menace l'identité nationale, pour la limiter il faut investir dans le codéveloppement" (STOICEADERAM, 2009, p.31).

2 - $O$ termo estrangeiro aparece entre aspas aqui e em alguns outros momentos do texto por uma questão de imprecisão conceitual, pois segundo a concepção jurídica francesa, o estrangeiro é alguém nascido no exterior, que vive na França e que não possui a nacionalidade francesa. Por outro lado, imigrante é um estrangeiro que deixou esta condição por obtenção da nacionalidade francesa através da naturalização. No entanto, nem sempre o reconhecimento jurídico acompanha o reconhecimento social, pois um "imigrante" pode ser visto pela sociedade de acolhimento como um "estrangeiro" não importando se adquiriu ou não a cidadania.

3 - Original em francês: "Pour un modèle français d'intégration".

4 - Estes dados resultam de estimativas realizadas pelas Embaixadas e pelos Consulados do Brasil sobre a presença de brasileiros vivendo em suas jurisdições.

5 - A pesquisa de campo financiada pela FAPESP na França foi realizada em 2010 e 2012. Foram feitas 86 entrevistas com brasileiros em diferentes cidades francesas. Também foram entrevistados brasileiros que viveram na França e retornaram ao Brasil ou que estavam morando em outro país. Acredito ser relevante dizer que a pesquisa seguiu todas as normas éticas recomendadas neste caso: todos os entrevistados foram informados sobre a pesquisa em curso e concordaram em participar do estudo. Além disso, me comprometi a preservar suas identidades de forma que eles serão mencionados através de pseudônimos.

6 - Os casamentos mistos são importantes para pensarmos a presença de brasileiros na França, segundo as estatísticas de estado civil divulgadas pelo INSEE, em 2010 foram registrados 498 casamentos mistos entre franceses e brasileiros. Entre os casamentos franco-brasileiros, $78 \%$ dos casos eram situações nas quais a cônjuge era brasileira e o marido francês.

7 - Entrevista realizada em Paris, França em 19/11/2010.

8 - Entrevista realizada em Lyon, França em 18/10/2012.

9 - Entrevista realizada em Aix-en-Provence, França em 29/06/2012.

10 - Entrevista realizada em Paris, França em 09/08/2012.

11 - Entrevista realizada em São Paulo, Brasil em 14/04/2011.

12 - Entrevista realizada em Marseille, França em 16/07/2012.

13 - Entrevista realizada em Marseille, França em 02/07/2012.

14 - Entrevista realizada em Campinas, Brasil em 23/06/2011.

15 - Entrevista realizada em São José dos Campos, Brasil em 08/06/2011.

\section{Referências}

ABUD, Tatiana. El Brasil de Francia: Representación de la Cultura Brasileña, la Imagen del País y la Conservación de Estereotipos. In: Seminário de Estudos sobre Imigração Brasileira na Europa, 1, Barcelona. Atas... Barcelona: Coletivo Brasil Catalunya, 2010, p. 265-272.

ALMEIDA REGO, Vânia e CHRISTIANO, Caio César. Ces drôles de Brésiliens - L'image du Brésilien dans les émissions humoristiques françaises et portugaises. DIRE - Diversités Recherches et Terrains, no 1, p. 38-45, mars 2012. Disponível em: <http://epublications.unilim.fr/ revues/dire/pdf/120 >. Acesso em: 15 dez. 2012. 
AMORIM, Marina Alves. Migração e casamento misto: o Brasil e 'a brasileira' no imaginário francês. In: MELLO, Ana Maria Lisboa de; MOREIRA, Maria Eunice e BERND, Zilá (orgs.) Pensamento francês e cultura brasileira. Porto Alegre: EdiPUCRS, 2009, p. 55-71.

ELIAS, Norbert e SCOTSON, John. Os estabelecidos e os outsiders: sociologia das relações de poder a partir de uma pequena comunidade. Rio de Janeiro: Ed. Jorge Zahar, 2000.

HAUT CONSEIL A L'INTEGRATION. Pour un modèle français d'intégration. Paris: La Documentation française, 1991. Disponível em: <http://www.ladocumentationfrancaise. fr>. Acesso em: 20 out. 2012.

HOBSBAWM, Eric J. A construção das nações. In: A era do capital: 1848-1875. São Paulo: Paz e Terra, 2005. p. 125-145.

ROSENFELD, Martin et al. Immigration brésilienne en Europe: dimension transnationale. Hommes \& Migrations, no 1281, p. 54-63, septembre-octobre 2009.

SALES, Teresa. O Brasil no contexto das novas migrações internacionais. Travessia-Revista do Migrante, São Paulo, no 21, p. 5-9, jan./abr. 1995.

SCHNAPPER, Dominique. L'intégration des migrants et de leurs descendants à la société nationale. Qu'est-ce que l'intégration? Paris: Gallimard, 2007, p. 71-129.

SIMAI, Szilvia. e BAENINGER, Rosana. Discurso, negação e preconceito: bolivianos em São Paulo. In: BAENINGER, Rosana. Imigração boliviana no Brasil. Campinas: Nepo/Unicamp, Fapesp, CNPq, UNFPA, 2012, p. 195-210.

STOICEA-DERAM, Ana Luana. "Immigration" et "identité nationale": une affaire de connexion. In: DESSAJAN, Séverine; HOSSARD, Nicolas et RAMOS, Elsa (dirs.) Immigration et identité nationale: une altérité revisitée. Paris: L'Harmattan, 2009, p. 29-45.

TRIBALAT, Michèle. Une estimation des populations d'origine étrangère en France en 1999. Population, vol. 59, no 1, p. 51-81, 2004. Disponível em: <http://www.cairn.info/revuepopulation-2004-1-page-51.htm>. Acesso em: 7 jul. 2012.

WEIL, Patrick. L'émergence d'une règle du jeu. La France et ses étrangers. Paris: Gallimard, 2004, p. 65-81.

\title{
RESUMO
}

A política de integração dos estrangeiros à sociedade francesa prevê a adesão voluntária dos novos membros à comunidade nacional, o que exige a aceitação dos valores republicanos franceses. Neste contexto, a situação dos brasileiros como estrangeiros na França é amenizada pelo fato de que estes compartilham os elementos da cultura ocidental, o que tende a repercutir em relativa facilidade de integração ao modo de vida francês. No entanto, existem estereótipos sobre o Brasil e os brasileiros, particularmente sobre as brasileiras, que sustentam estigmas e desta forma alimentam práticas discriminatórias. A partir de entrevistas semiestruturadas realizadas com imigrantes brasileiros na França e com ex-imigrantes retornados ao Brasil, este artigo reflete sobre a experiência de brasileiros como "estrangeiros" na França, considerando os diversos processos de "integração" e de "discriminação" vivenciados por estes brasileiros/as.

Palavras-chave: brasileiros na França; integração; preconceito.

\begin{abstract}
The policy for the integration of foreigners into French society aims for the submission of the new members to the national community. It requires the acceptance of the French republican values. In this context, the situation of the Brazilians as foreigners in France is mitigated by the fact that they share elements of Western culture. This helps Brazilians to integrate into the French way of life with ease. Nevertheless, there are stereotypes about
\end{abstract}


Brazil and Brazilians, particularly about Brazilian women, that sustain stigmas and thus feed discriminatory practices. Based on semi-structured interviews with Brazilian immigrants in France and migrants who have lived in France and have returned to Brazil, this article examines the experience of Brazilians as "foreigners" in France considering the various processes of "integration" and "discrimination" experienced by these Brazilian men and women.

Keywords: brazilians in France; integration; prejudice. 